\title{
Preparation of Porous Chitosan Microsphere Absorbent and Research on Its Absorption Ability for $\mathrm{Cu}^{2+}$ and $\mathrm{Zn}^{2+}$
}

\author{
Cuirong Zhang (Corresponding author) \& Zhenyu Jia \\ Department of Chemistry and Chemical Engineering \\ Zhongkai Agriculture Engineering College, Guangzhou, Guangdong 510230, China \\ Tel: 86-150-1338-3998Ｅ-mail: zcr19661115@163.com
}

\begin{abstract}
An amino chitosan absorbent has been prepared with monoethylamine, chitosan, catalyst, cross-linking agent, hydroxylpropyl chlorination agent and amination agent. This paper discusses the effect of monoethylamine modification on the amino content in chitosan absorbent, as well as its effect on the absorption capacity of absorbent for $\mathrm{Cu}^{2+}$ and $\mathrm{Zn}^{2+}$; and investigates the absorption kinetics of chitosan and amino chitosan for $\mathrm{Cu}^{2+}$ and $\mathrm{Zn}^{2+}$. The results indicate that the amino content of modified porous microspheric chitosan is higher than that of chitosan; its absorption capacity for $\mathrm{Cu}^{2+}$ and $\mathrm{Zn}^{2+}$ increases with the rise of temperature and changes with $\mathrm{pH}$, and there is no obvious difference in absorption capacity of $\mathrm{Zn}^{2+}$ between chitosan and modified chitosan.
\end{abstract}

Keywords: Chitosan, Absorbent, Amination

The major use of chitosan is to purify wastewaters. At present, people are growing concerned that heavy metals, insecticides and their accumulations in food chains will cause ecological damages and health hazard. Therefore, wastewater is required to be treated before discharge. Amino group in chitosan can form a coordinate-covalent bond with metal ion. As a result, chitosan has been widely applied in wastewater treatment. Chitosan exhibits excellent properties in collecting heavy metal ions (Jeon C et al, 2005, p. 3938-3944; Rojas G et al, 2005, p. 31-36). Amino group and hydroxyl group in chitosan molecular can react with metal ions, such as $\mathrm{Hg}^{2+}, \mathrm{Cu}^{2+}$ and $\mathrm{Zn}^{2+}$, to form stable chelates (Guibal E et al, 2002, p. 149-163; Ruiz M et al, 2000, p. 155-173; Guibal E et al, 1999, p. 4011-4022), and effectively remove toxic heavy metal ions from industrial wastewaters (Guibal E et al, 1999, p. 4011-4022). Therefore, application of chitosan has been of great significance in environmental protection.

There has been a great deal of research in this field home and abroad. Although starting relatively late in China, it has developed rather rapidly, and got many achievements. Amino group and hydroxyl group in chitosan molecular exhibit good activity against metal ions, and can introduce functional groups onto chitosan by acylation, etherification, $\mathrm{N}$-alkylation, esterification or other reactions. The obtained derivatives have better physical and chemical properties, higher solubility, and stronger chelating ability towards heavy metal ions. This study has increased the amino content of chitosan and improved its absorption ability for $\mathrm{Cu}^{2+}$ and $\mathrm{Zn}^{2+}$ by modification of chitosan with ethylamine.

\section{Experiment}

\subsection{Reagents and equipments}

(1) Reagents

Chitosan with a deacetylation degree of 90.3\%, from Shanghai Kabo Industrial and Trading Company; monoethylamine, from Shanghai Linger Chemical Co., Ltd.; copper nitrate trihydrate, from Taiyuan Xinli Chemical Co., Ltd.; zinc nitrate hexahydrate, from Shanghai Shicheng Chemical Co., Ltd.; oxalic aldehyde with mass fraction of $40 \%$, from Guangzhou Wanyou Chemical Co., Ltd.; epichlorohydrin (AR), from Shanghai Reagent Company; sodium lauryl sulfate, from Shanghai Chemsun Trade Co., Ltd.; isopropanol (AR), acetone (AR) and acetic acid (AR), from Tianjin Damao Chemical Reagent Factory; ethyl acetate, from Yixing Huihuang Chemical Reagent Factory; ethanol, from Guangdong Zhongneng Alcohol Co., Ltd.; and self-made distilled water.

(2) Equipments

Nicolet-410 infrared spectrometer, PE 300 atomic absorption spectrophotometer, SHA-B water bath constant temperature oscillator, DZF-6050 vacuum dryer, all-glass syringe, and freeze dryer. 


\subsection{Preparation method}

\subsubsection{Preparation of metal ion solution}

Accurately weigh and dissolve $23.7734 \mathrm{~g}$ of $\mathrm{Cu}\left(\mathrm{NO}_{3}\right)_{2} \cdot 3 \mathrm{H}_{2} \mathrm{O}$, then dilute to the mark in a $250 \mathrm{~mL}$ volumetric flask to obtain a $\mathrm{Cu}^{2+}$ standard solution with concentration of $6.2523 \mathrm{~g} / \mathrm{L}(0.09840 \mathrm{~mol} / \mathrm{L})$, which is in turn diluted 10 times for further use.

Accurately weigh and dissolve $29.2710 \mathrm{~g}$ of $\mathrm{Zn}\left(\mathrm{NO}_{3}\right)_{2} \cdot 6 \mathrm{H}_{2} \mathrm{O}$, then dilute to the mark in a $250 \mathrm{~mL}$ volumetric flask to obtain a $\mathrm{Zn}^{2+}$ standard solution with concentration of $6.4324 \mathrm{~g} / \mathrm{L}(0.09840 \mathrm{~mol} / \mathrm{L})$, which is in turn diluted 10 times for further use.

\subsubsection{Preparation of porous chitosan microsphere (CS)}

Weigh $3 \mathrm{~g}$ chitosan with deacetylation degree of $90.3 \%$ into flask, and dissolve with $100 \mathrm{~mL} 11 \%$ solution of acetic acid. Add $1.5 \mathrm{~mL}$ sodium dodecyl sulfate (emulsifier) into the above-formulated solution to obtain a $3 \%$ chitosan colloid solution, which is in turn placed at room temperature overnight to dissolve completely. Extract a certain amount of chitosan colloid solution with a syringe, and drop at a constant speed into a coagulant, which is prepared by adding 15 $\mathrm{mL}$ acetic acetate into $250 \mathrm{~mL} 2.8 \%$ solution of $\mathrm{NaOH}$. The obtained sample is placed at room temperature for $2 \mathrm{~h}$, and washed repeatedly with deionized water to get neutral chitosan microsphere, which is freeze dried for further use.

Add $2.5 \mathrm{~mL}$ oxaldehyde crosslinking agent into the above-mentioned chitosan microsphere, and stir intermittently for 3 $\mathrm{h}$ to get porous chitosan microsphere, which is in turn washed repeatedly with water and ethanol to remove the unreacted crosslinking agent, and air dried for further use.

\subsubsection{Preparation of monoethylamine modified chitosan microsphere (ECS)}

Introduce the prepared CS into $60 \mathrm{~mL}$ isopropanol in a $250 \mathrm{~mL}$ flask to obtain a suspension with the chitosan microsphere floating on the top surface. Add a mixture of $5 \mathrm{~mL}$ epichlorohydrin and $100 \mathrm{~mL}$ water solution of acetone (the volume ratio of acetone to water is $1: 1$ ) into the suspension, which is in turn stirred at $60{ }^{\circ} \mathrm{C}$ for $30 \mathrm{~h}$, and let stand for separation. The solid phase is transferred into $150 \mathrm{~mL}$ water solution of ethanol (the volume ratio of water to ethanol is 1:1), followed by mixing with $6 \mathrm{~mL}$ monoethylamine. The obtained mixture is stirred at $50{ }^{\circ} \mathrm{C}$ for $10 \mathrm{~h}$, then filtrated, washed and vacuum dried to get ECS. The reaction procedure is expressed with following formula.

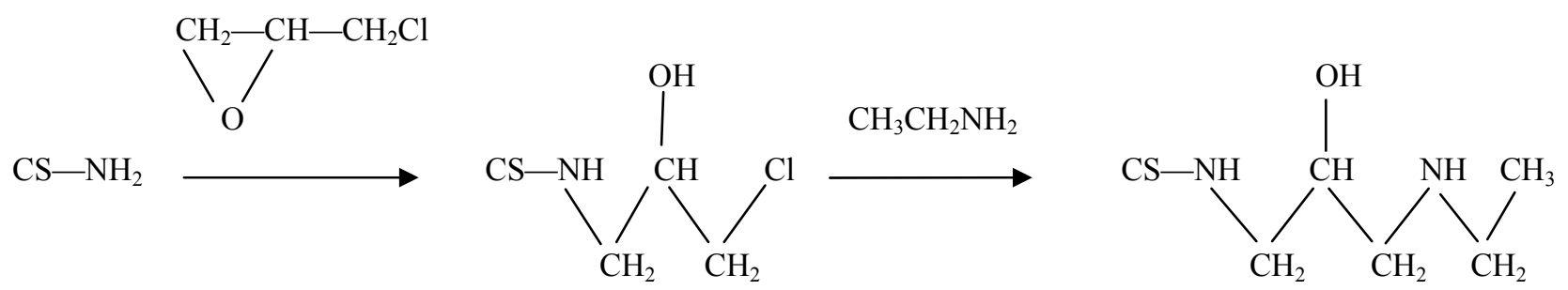

\subsection{Analysis methods}

\subsubsection{IR analysis}

The sample is dried, crushed and pressed with $\mathrm{KBr}$ for IR spectrum measurement and interpretation.

\subsubsection{Determination of amino content in ECS}

Determine the amino content in ECS by volumetric method. Introduce $0.1 \mathrm{~g}$ ECS into $20 \mathrm{~mL} 0.5 \mathrm{~mol} / \mathrm{L}$ solution of $\mathrm{HCl}$, keep stationary for $48 \mathrm{~h}$ until the reaction reaches equilibrium, then titrate with $0.05 \mathrm{~mol} / \mathrm{L}$ solution of $\mathrm{NaOH}$. Calculate the molality of amino $(\mathrm{b}, \mathrm{mmol} / \mathrm{g})$ with following formula.

$$
b=20\left(C_{0}-C_{1}\right) / 0.1
$$

Here, $C_{0}(\mathrm{~mol} / \mathrm{L})$ and $C_{1}(\mathrm{~mol} / \mathrm{L})$ represent the initial concentration and equilibrium concentration, respectively.

\subsubsection{Determination of absorption of metal ions}

(1) Determination of absorption of $\mathrm{Cu}^{2+}$

Determine the absorption of $\mathrm{Cu}^{2+}$ with PE 300 atomic absorption spectrophotometer under the conditions of $3.0 \mathrm{~L} / \mathrm{min}$ ethyne flow rate, $10.0 \mathrm{~L} / \mathrm{min}$ air flow rate, $0.7 \mathrm{~mm}$ slit width, $324 \mathrm{~nm}$ wavelength, and distilled water as blank.

(2) Determination of absorption of $\mathrm{Zn}^{2+}$

Determine the absorption of $\mathrm{Zn}^{2+}$ with PE 300 atomic absorption spectrophotometer under the conditions of $3.0 \mathrm{~L} / \mathrm{min}$ ethyne flow rate, $10.0 \mathrm{~L} / \mathrm{min}$ air flow rate, $0.7 \mathrm{~mm}$ slit width, $213.0 \mathrm{~nm}$ wavelength, and distilled water as blank. 


\section{Results and discussions}

\subsection{IR spectrum measurements and interpretations of different chitosans}

Figure 1 3 exhibit the IR spectrums of oxaldehyde-crosslinked chitosan, epichlorohydrin-modified chitosan and monoethylamine-modified chitosan, respectively.

Figure 1 exhibits a characteristic peak of Schiff's base at 1660 1680 $\mathrm{cm}^{-1}$, which indicates that chitosan has crosslinked with oxaldehyde to obtain a Schiff's base. Figure 2 exhibits a characteristic peak of $\mathrm{C}=\mathrm{N}$ at $1660 \sim 1680 \mathrm{~cm}^{-1}$ and a characteristic peak of $\mathrm{C}-\mathrm{Cl}$ at $690 \sim 670 \mathrm{~cm}^{-1}$, however no characteristic peak of $\mathrm{C}-\mathrm{O}-\mathrm{C}$ at $1280 \sim 1230 \mathrm{~cm}^{-1}$, which indicates that chitosan has reacted with epichlorohydrin. The characteristic peak of $\mathrm{C}-\mathrm{Cl}$ at $690 \sim 670 \mathrm{~cm}^{-1}$ has disappeared in figure 3, which demonstrates that $\mathrm{Cl}$ has been substituted by $\mathrm{N}$ in monoethylamine to obtain an absorbent of high amino content.

\subsection{Determination of amino content in ECS}

Table 1 shows the amino contents in chitosan and its derivatives.

\subsection{Absorption of metal ions}

\subsubsection{Absorption dynamics of chitosan and modified chitosan for $\mathrm{Zn}^{2+}$ and $\mathrm{Cu}^{2+}$}

Weigh two samples of $0.5 \mathrm{~g}$ amino chitosan each in conical flasks, introduce the self-made solutions of $\mathrm{Cu}^{2+}$ and $\mathrm{Zn}^{2+}$, respectively, and seal them well, which are in turn placed in an oscillator of constant temperature, and vibrated for absorption under the conditions of $25^{\circ} \mathrm{C}$ and vibrating rate of $100 \mathrm{r} / \mathrm{min}$. Determine the concentrations of $\mathrm{Cu}^{2+}$ and $\mathrm{Zn}^{2+}$ with an atomic absorption spectrophotometer per hour. Calculate the absorption capacity of chitosan for $\mathrm{Cu}^{2+}$ and $\mathrm{Zn}^{2+}$ with following formula.

$$
Q=\left(C_{0}-C_{\mathrm{e}}\right) \times V / m
$$

Here, $Q(\mathrm{mg} / \mathrm{g})$ represents the absorption capacity; $C_{0}(\mathrm{mg} / \mathrm{mL})$ represents the initial concentration of metal ion in solution; $C_{\mathrm{e}}(\mathrm{mg} / \mathrm{mL})$ represents the equilibrium concentration of metal ion in solution; $V(\mathrm{~mL})$ represents the volume of solution; and $m(\mathrm{~g})$ represents the dosage of chitosan.

From figure 4 to figure 7, we can see that the absorption of modified chitosan for $\mathrm{Cu}^{2+}$ and $\mathrm{Zn}^{2+}$ reaches equilibrium after 8 9 hours of reaction; and the absorption of chitosan for $\mathrm{Zn}^{2+}$ changes little after modification, however, that for $\mathrm{Cu}^{2+}$ changes obviously. It's probably because that $-\mathrm{NH}_{2}$ and adjacent $-\mathrm{OH}$ in chitosan chelate with $\mathrm{Cu}^{2+}$ to form a stable five-member ring, and linear-chain chitosan turns into a crosslinked polymer, this polymer will consist of more $-\mathrm{NH}_{2}$ after modification, which further increases the absorption capacity for $\mathrm{Cu}^{2+}$; However, the absorption for $\mathrm{Zn}^{2+}$ is realized mainly through $-\mathrm{OH}$, and $-\mathrm{OH}$ content changes little after modification, therefore, the absorption of chitosan for $\mathrm{Zn}^{2+}$ changes little after modification.

\subsubsection{Effect of temperature on absorption of modified chitosan for $\mathrm{Zn}^{2+}$ and $\mathrm{Cu}^{2+}$}

Dilute $25 \mathrm{~mL}$ standard solutions of $\mathrm{Zn}^{2+}$ and $\mathrm{Cu}^{2+}$ to the marks with distilled water in $250 \mathrm{~mL}$ volumetric flasks, respectively. Accurately weigh two samples of $0.15 \mathrm{~g}$ modified chitosan each in $250 \mathrm{~mL}$ conical flasks, and introduce $150 \mathrm{~mL}$ above-diluted solutions to obtain chitosan solutions with concentration of $0.1 \%$. Seal them well, then place them into water bath of constant temperature of $5{ }^{\circ} \mathrm{C}, 10{ }^{\circ} \mathrm{C}, 15{ }^{\circ} \mathrm{C}, 20^{\circ} \mathrm{C}$ and $25^{\circ} \mathrm{C}$, respectively. Stir at $80 \mathrm{r} / \mathrm{min}$ for 24 $\mathrm{h}$, and measure the concentrations of $\mathrm{Zn}^{2+}$ and $\mathrm{Cu}^{2+}$ with atomic absorption spectrophotometer.

From figure 8, we can see that the absorption capacity of modified chitosan for $\mathrm{Zn}^{2+}$ or $\mathrm{Cu}^{2+}$ increases with the rise of temperature. The absorption capacity of modified absorbent for $\mathrm{Zn}^{2+}$ increases $41.5 \%$ from $97 \mathrm{mg} / \mathrm{g}$ to $139 \mathrm{mg} / \mathrm{g}$, and that for $\mathrm{Cu}^{2+}$ increases $43.2 \%$ from $157 \mathrm{mg} / \mathrm{g}$ to $226 \mathrm{mg} / \mathrm{g}$. It's probably because at high temperature, the absorbent molecular and absorbed ions move much faster, the interactions among molecular decrease, and the metal ions can move into absorbent more easier. As a result, the contact area between absorbent and metal ions increases, which leads to the increase of the absorption capacity of absorbent for metal ions. On the other hand, the absorption here is an endothermic procedure, therefore, the rise of temperature promotes the absorption of absorbent for metal ions.

\subsubsection{Effect of $\mathrm{pH}$ on absorption of modified chitosan for $\mathrm{Zn}^{2+}$ and $\mathrm{Cu}^{2+}$}

Dilute $10 \mathrm{~mL}$ standard solutions of $\mathrm{Zn}^{2+}$ and $\mathrm{Cu}^{2+}$ to $100 \mathrm{~mL}$ with distilled water in $150 \mathrm{~mL}$ flasks, respectively, and prepare five samples for each group. Add $1 \mathrm{~g}$ modified chitosan into each sample, and place them in an oscillator with constant temperature of $20{ }^{\circ} \mathrm{C}$, vibrate for $24 \mathrm{~h}$. Measure the concentrations of $\mathrm{Zn}^{2+}$ and $\mathrm{Cu}^{2+}$ with atomic absorption spectrophotometer, and calculate their absorption capacity.

From figure 9, we can see that the absorption capacity increases with the rise of $\mathrm{pH}$ at the beginning, and reaches the maximum when $\mathrm{pH}$ is $6 \sim 7$, then decreases with the further increase of $\mathrm{pH}$. It indicates that $\mathrm{pH}$ has an obvious effect on the absorption capacity. It's probably because the concentration of $\mathrm{H}^{+}$is high when $\mathrm{pH}$ is less than 6 , and $\mathrm{H}^{+}$reacts with $-\mathrm{NH}_{2}$ to form $-\mathrm{NH}_{3}^{+}$, which causes the decline of effective concentration of $-\mathrm{NH}_{2}$, and then leads to the decline of 
absorption capacity. However, the concentration of $\mathrm{OH}^{-}$is high when $\mathrm{pH}$ is higher than 8 , and $\mathrm{OH}^{-}$reacts with $\mathrm{Zn}^{2+}$ or $\mathrm{Cu}^{2+}$ to form the corresponding precipitations, which causes the decline of absorption capacity.

\section{Conclusion}

(1) A new amino absorbent has been prepared by crosslinking, hydroxylpropyl chlorination and amination of chitosan. This new absorbent contains much more $-\mathrm{NH}_{2}$, which causes the increase of absorption capacity.

(2) The absorption capacity of chitosan for $\mathrm{Zn}^{2+}$ changes little after modification, however, that for $\mathrm{Cu}^{2+}$ changes obviously. It's probably because the absorption center in chitosan for $\mathrm{Cu}^{2+}$ is $-\mathrm{NH}_{2}$, however, that for $\mathrm{Zn}^{2+}$ is $-\mathrm{OH}$.

(3) The absorption capacity of the modified absorbent for $\mathrm{Zn}^{2+}$ or $\mathrm{Cu}^{2+}$ increases obviously with the rise of temperature.

(4) The absorption capacity increases with the rise of $\mathrm{pH}$ at the beginning, and reaches the maximum when $\mathrm{pH}$ is $6 \sim 7$, then decreases with the further increase of $\mathrm{pH}$. It indicates that $\mathrm{pH}$ has an obvious effect on the absorption capacity.

\section{References}

E Guibal, N Von Offenberg Sweeney \& T Vincent. (2002). Sulfur derivatives of chitosan for palladium sorption. Reactive \& Functional Polymers, 50(2), 149-163.

Graciela Rojas, Jorge Silva, Jaime A Flores, Angélica Rodriguez, Martha Ly \& Holger Maldonado. (2005). Adsorption of chromium onto cross-linked chitosan. Separation and Purification Technology, 44(1), 31-36.

Guibal E, Vincent T \& Larkin A. (1999). Chistosan sorbents for platihum recovery from dilute solutions. Ind Eng Chem Res, 38(10), 4011-4022.

Jeon C \& Park K H. (2005). Adsorption and desorption characteristics of mercury( II) ions using aminated chitosan bead. Water Res, 39(16), 3938-3944.

Ruan, Xinchao \& Du, Yumin. (2003). Treatment of dyeing wastewater with chitosan and its derivatives. Modern Chemical Industry, 23, 100-102.

Ruiz M, Sastre A M \& Guibal E. (2000). Palladium sorption on glutaraldehyde-crosslinked chitosan. Reactive \& Functional Polymers, 45(3), 155-173.

Table 1. Amino contents in chitosan and its derivatives

\begin{tabular}{|c|c|}
\hline Products & Amino content (mmol/g) \\
\hline Chitosan & 5.3 \\
\hline Oxaldehyde-modified chitosan & 4.2 \\
\hline Epichlorohydrin-modified chitosan & 3.9 \\
\hline Monoethylamine-modified chitosan & 6.5 \\
\hline
\end{tabular}

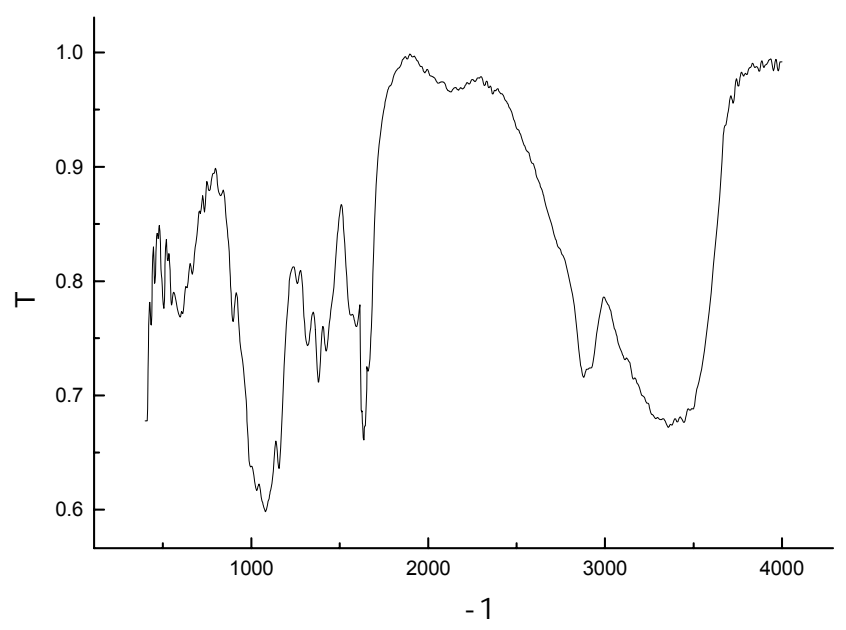

There appear peaks at 3550 3000 $\mathrm{cm}^{-1}\left(-\mathrm{OH},-\mathrm{NH}_{2}\right), 1170 \sim 1000 \mathrm{~cm}^{-1}(\mathrm{C}-\mathrm{O})$ and $1660 \sim 1680 \mathrm{~cm}^{-1}(\mathrm{C}=\mathrm{N})$

Figure 1. IR spectrum of oxaldehyde-crosslinked chitosan 


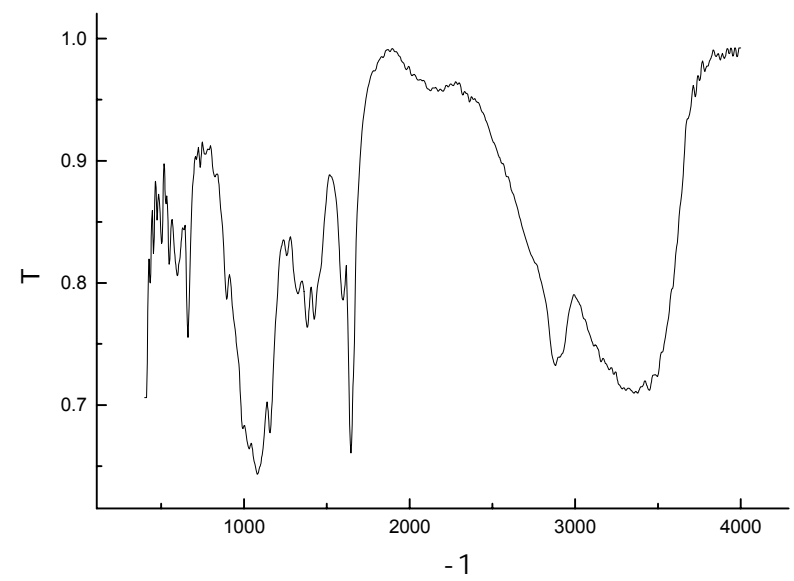

There appear peaks at 3550 3000 $\mathrm{cm}^{-1}\left(-\mathrm{OH},-\mathrm{NH}_{2}\right), 1170 \sim 1000 \mathrm{~cm}^{-1}(\mathrm{C}-\mathrm{O}), 1660 \sim 1680 \mathrm{~cm}^{-1}(\mathrm{C}=\mathrm{N})$ and $690 \sim 670 \mathrm{~cm}^{-1}(\mathrm{C}-\mathrm{Cl})$

Figure 2. IR spectrum of epichlorohydrin-modified chitosan

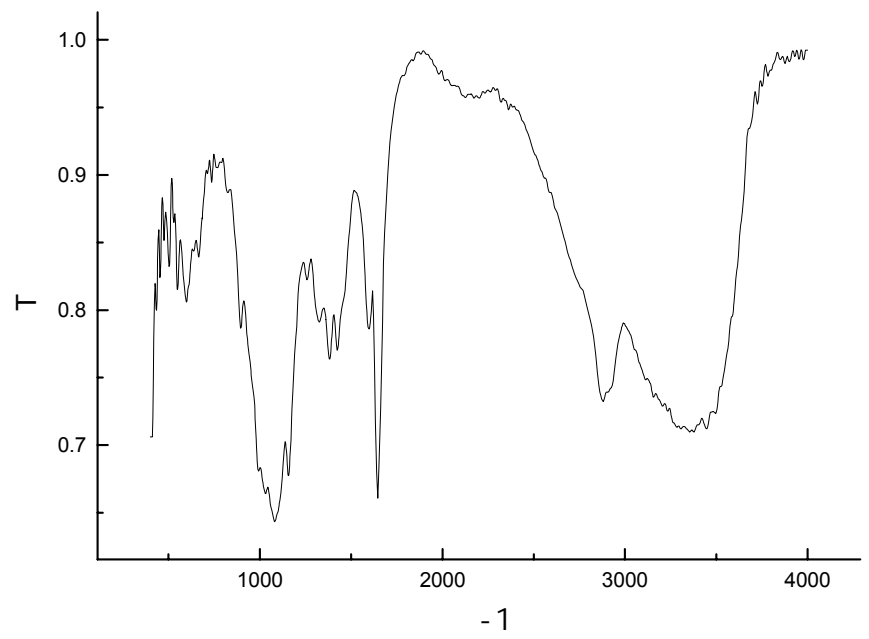

There appear peaks at 3550 3000 $\mathrm{cm}^{-1}\left(-\mathrm{OH},-\mathrm{NH}_{2}\right), 1170 \sim 1000 \mathrm{~cm}^{-1}(\mathrm{C}-\mathrm{O})$ and $1660 \sim 1680 \mathrm{~cm}^{-1}(\mathrm{C}=\mathrm{N})$

Figure 3. IR spectrum of monoethylamine-modified chitosan 


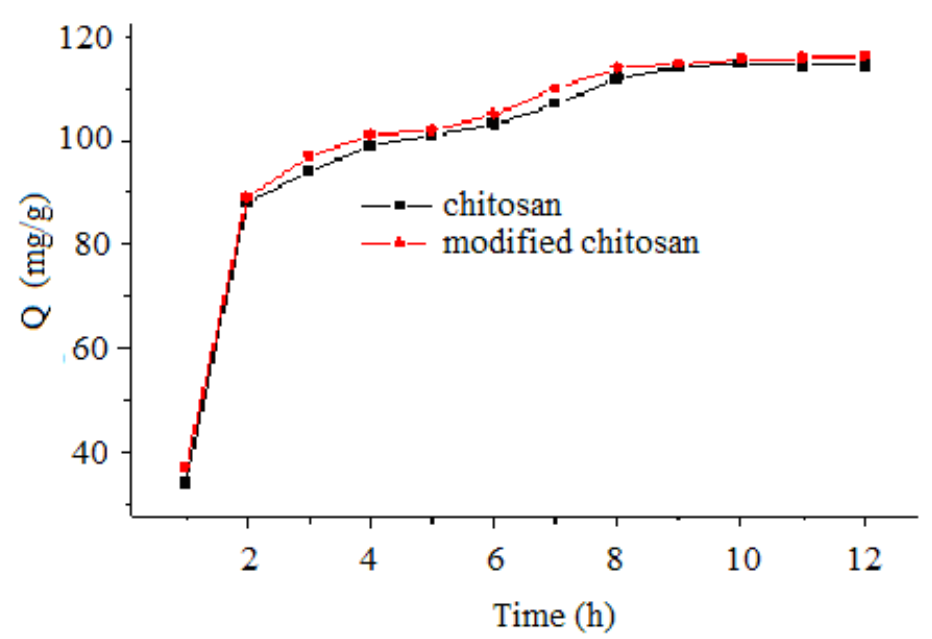

Figure 4. Absorption capacity of chitosan and modified chitosan for $\mathrm{Zn}^{2+}$

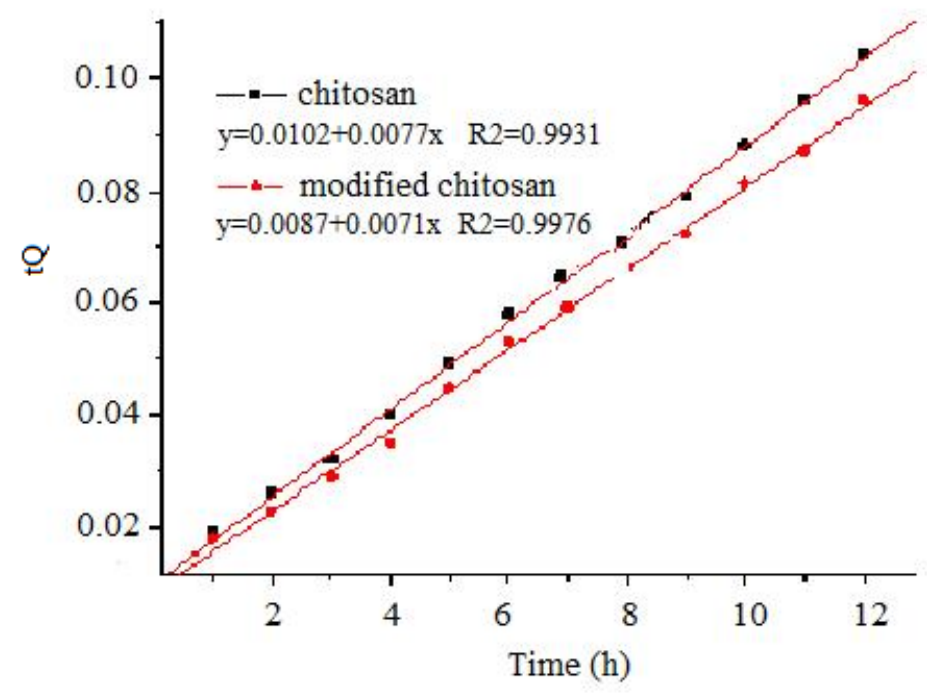

Figure 5. tQ vs. time curve of $\mathrm{Zn}^{2+}$ 


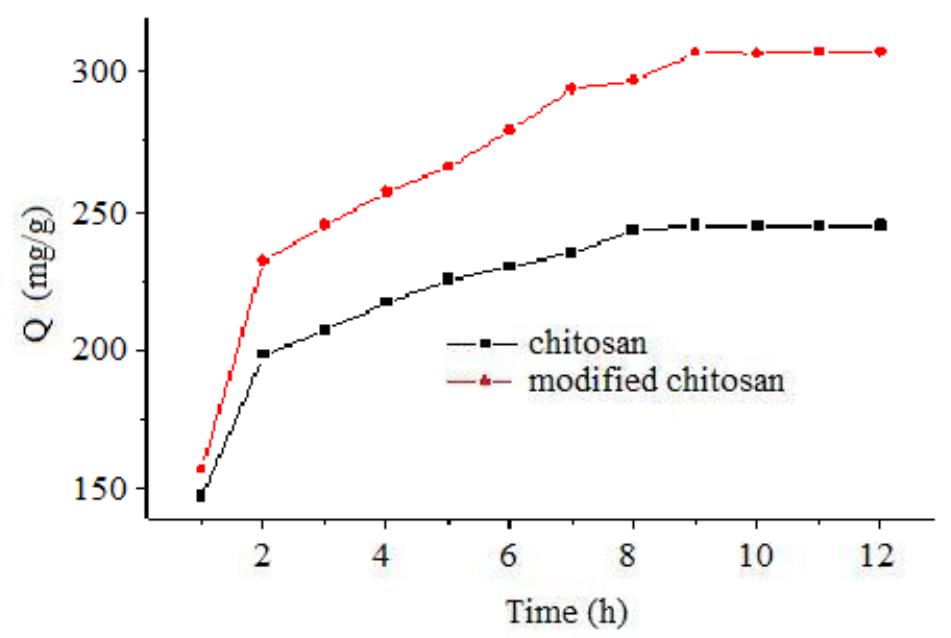

Figure 6. Absorption capacity of chitosan and modified chitosan for $\mathrm{Cu}^{2+}$

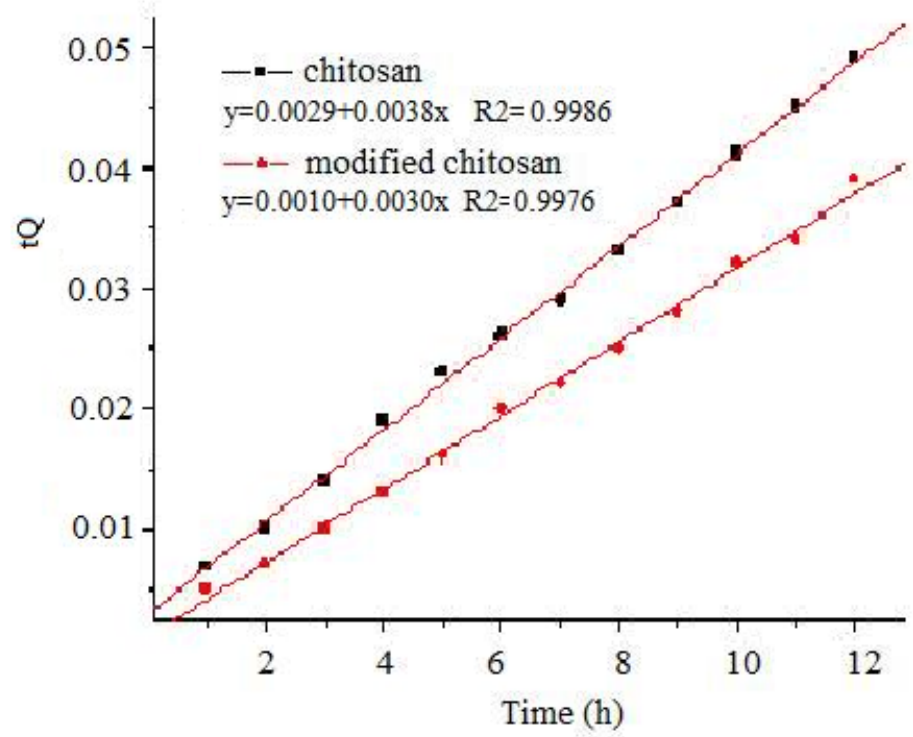

Figure 7. tQ vs. time curve of $\mathrm{Cu}^{2+}$ 


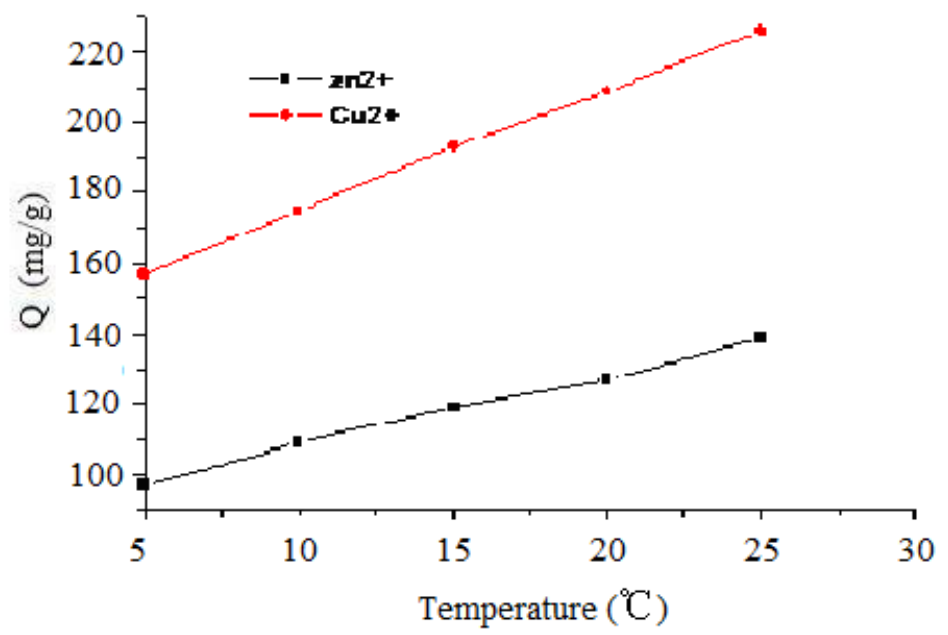

Figure 8. Effect of temperature on absorption of absorbents for $\mathrm{Zn}^{2+}$ and $\mathrm{Cu}^{2+}$

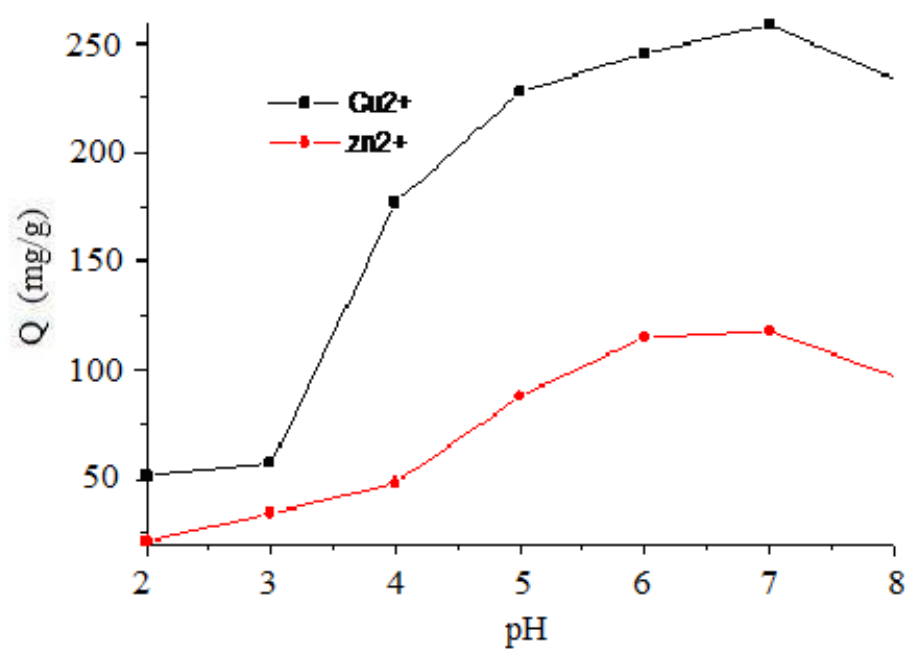

Figure 9. Effect of $\mathrm{pH}$ on absorption of absorbents for $\mathrm{Zn}^{2+}$ and $\mathrm{Cu}^{2+}$ 